\title{
Sobre altas habilidades/superdotaçáo: o direito de ser diferente na escola
}

\author{
Anna M. C. Benite* \\ Claudio R. M. Benite** \\ Elaisse M. Alves*** \\ Karina M. M. B. Cunha**** \\ Marcos V. R. Procopio ${ }^{* * * * *}$
}

\section{Resumo}

O paradigma da inclusão implica a reestruturaçáo dos sistemas de ensino a partir do reconhecimento da diversidade da sala de aula. Desta forma, estudos direcionados a pessoas com necessidades educativas especiais (NEE), especificamente com altas habilidades/ superdotação, na perspectiva da inclusão escolar, devem ser abordados de forma singular nos cursos de formação de professores, instância que também deve ser responsabilizada pela preparaçáo de recursos humanos para essa nova demanda e na qual tais questóes podem e devem ser problematizadas. Neste trabalho versamos sobre consideraçôes a respeito do conceito de altas habilidades/superdotação, apresentando um breve panorama histórico sobre o atendimento a estes alunos. Esclarecimentos sobre as políticas públicas educacionais nacionais que orientam esse atendimento e sobre o Núcleo de Atividades de Altas Habilidades/Superdotação (NAAH/S), que surgiu recentemente com o intuito de atender essa especificidade da inclusão escolar, completam nossas consideraçóes.

Palavras-chave: altas habilidades/superdotação, inclusão escolar.

* Doutora em Ciências/Química pela Universidade Federal de Goiás (UFG), Instituto de Química; coordenadora do Laboratório de Pesquisas em Educação Química e Inclusão/LPEQI (UFG). E-mail: anna@quimica.ufg.br

** Doutor em Química; colaborador do Laboratório de Pesquisas em Educação Química e Inclusão/ LPEQI (UFG); docente da Universidade Estadual de Goiás (UEG), Unidade Universitária de Ciências Exatas e Tecnológicas (UnUCET), curso de Química, Licenciatura. E-mail: claudio. benite@ueg.br

*** Especialista em atendimento especializado em AH/SD; docente da Secretaria da Educação do Estado de Goiás, Coordenação de Ensino Especial (COEE). E-mail: elaissem@yahoo.com.br

**** Mestranda em Linguística no Instituto de Ciências Humanas e Letras, UFG; docente da Secretaria da Educação do Estado de Goiás, Coordenação de Ensino Especial (COEE). E-mail: karina_mir@hotmail.com

***** Mestre em Educação em Ciências e Matemática pela Universidade Federal de Goiás (UFG); colaborador do Laboratório de Pesquisas em Educação Química e Inclusão/LPEQI (UFG). Email: quanticis@gmail.com 
Exceptional aptitude/giftedness: the right to be different at school

\begin{abstract}
The inclusion paradigm involves the restructuration of education systems, based on the recognition of diversity in the classroom. Thus, from the perspective of inclusive education, studies for people with special educational needs, specifically those with exceptional aptitude/ giftedness should be addressed in a special way in teacher formation courses. Such courses should also be responsible for preparing human resources to meet this new demand and such issues can and should be problematized in these courses. This study deals with the concept of exceptional aptitude/giftedness and presents a brief historical overview on how to deal with these students. It also provides explanations on the national educational policies which underlie this care and the Center for Exceptional aptitude/giftedness which was recently founded to attend to this specific aspect of inclusive education.
\end{abstract}

Keywords: exceptional aptitude/giftedness, inclusive education.

\title{
Panorama histórico sobre o atendimento às altas habilidades/ superdotaçáo
}

A prática de atendimento educacional, no caso das altas habilidades/ superdotação (AH/SD), não se resume a poucos anos, nem mesmo a décadas. Existem registros que datam do ano 387 a.C., em que a academia Platônica selecionava pessoas por sua capacidade intelectual e suas habilidades físicas, não levando em consideração sua classe social e sua formação (GAMA, 2006). Há mais de 4000 anos a China selecionava as crianças mais aptas intelectualmente para que recebessem uma educação diferenciada, o que não diferia da educação superior oferecida na antiga Roma, que se destinava apenas aos "mais capazes" (REZUNLLI, 1978). No século XVII, o Japão oferecia educaçáo diferenciada aos alunos que pertenciam a classe social privilegiada (GAMA, 2006).

No continente europeu, disseminaram-se em vários locais produçôes e açóes que contemplavam as AH/SD. Em 1910, surgem os primeiros textos na Iugoslávia sobre o assunto. Na Holanda, em 1921, é criada a primeira instituição responsável por educar e formar alunos com uma "inteligência superior". Logo depois, William Stern elabora os testes de quociente de inteligência (QI) e, na Inglaterra, Galton realiza uma pesquisa que organiza os testes de inteligência para serem utilizados na identificação das AH/ SD (GAMA, 2006). Esses testes favoreciam os alunos das classes sociais privilegiadas acreditando terem uma melhor formação e apresentarem 
maior aptidão, dando a impressão de atendimento elitista ao alunos com AH/SD (PEREZ, 2003).

A partir do ano de 1970, no continente asiático, países como Coreia, Taiwan, Singapura, China e Japão demonstraram a preocupaçáo com a formação de indivíduos talentosos. Vale considerar que entre todos os países que compóem a regiáo do continente asiático, conhecida como Oriente Médio, somente Israel materializou o interesse por desenvolver um sistema que atendesse as pessoas com AH/SD (GAMA, 2006).

No continente americano, o processo de atendimento às AH/SD teve início nos Estados Unidos (USA) quando Louis Terman, da Univerdade de Stanford, adaptou o teste de Binet com o objetivo de medir o QI, que passou a ser conhecido, posteriormente, como teste de Stanford-Binet. Por sua vez, Leta Hollingworth, da Universidade de Columbia, defendia uma educação própria para os alunos com $\mathrm{AH} / \mathrm{SD}$, que pouco tempo depois foi reconhecida no movimento de "Educação para Todos".

No Brasil, as primeiras publicaçóes e/ou produçóes referentes às $\mathrm{AH} /$ $\mathrm{SD}$, de gênero político e/ou científico, datam do período compreendido entre os anos de 1926 e 1931, quando Leoni Kaseff (assistente técnico da Universidade do Rio de Janeiro e catedrático do Liceu Nilo Peçanha, relator do texto legislativo, marco da política pública e privada da época) discutiu a educação para os "supernormais". Esse tema foi central na discussão da reforma do ensino no Rio de Janeiro, em 1929, evidenciando a importância de se incluir a superdotação nos atendimentos especializados da época (BRASIL, 1999). De acordo com Delou (apud FLEITH, 2007), "esta iniciativa, contudo, não garantiu o direito declarado na legislação [desse estado], uma vez que não foi acompanhada de uma política pública estadual e federal que universalizasse o atendimento escolar a estes alunos" (p. 27).

Ainda nesse período (1927), em Minas Gerais, orientada pela reforma Francisco Campos, que tinha como objetivo uma educação centrada numa formação humana, a pesquisadora Helena Antipoff, auxiliada por suas alunas-professoras, utilizava o método de observação natural conjuntamente com os testes de Binet e Simon, com a intenção de avaliar as capacidades cognitivas das crianças (RAFANTE e LOPES, 2006). Cabe esclarecer que o método de observação natural foi desenvolvido pelo psicólogo russo Alexandre Lazursky, visando ao acompanhamento da criança em seu ambiente escolar, tanto em sala de aula como no intervalo recreativo, com a intenção de identificar alguns aspectos de sua personalidade. 
Em 1971 foi aprovada a Lei de Diretrizes e Bases da Educação Nacional, lei n. 5.692/1971, referenciando em seu art. $9^{\circ}$ as AH/SD:

Art. 9:

Os alunos que apresentem deficiências físicas ou mentais, os que se encontrem em atraso considerável quanto à idade regular de matrícula e os superdotados deverão receber tratamento especial, de acordo com as normas fixadas pelos competentes Conselhos de Educação. (BRASIL, 1971)

Em 1996, a Lei de Diretrizes e Bases da Educaçâo Nacional, lei n. 9.394/1996, incluiu os excepcionais em seus textos, reconhecendo as necessidades educativas especiais dos alunos com AH/SD em seu Capítulo V, Art. 59, Parágrafo II, ao normatizar a "terminalidade específica para aqueles que não puderem atingir o nível exigido para a conclusão do ensino fundamental, em virtude de suas deficiências, e aceleraçáo para concluir em menor tempo o programa escolar para os superdotados" (BRASIL, 1996).

Dessa forma, em 2005, com uma política pública baseada na LDB/96 e em documentos como a Declaração de Salamanca, foi instituído o Núcleo de Atividades de Altas Habilidades/Superdotaçáo (NAAH/S), numa parceria entre a Unesco, o Ministério da Educação/Secretaria de Educação Especial (SEESP) e a Secretaria da Educação (SEE) da capital de cada Estado, com o objetivo de

promover a identificação, o atendimento e o desenvolvimento dos alunos com altas habilidades/superdotação das escolas públicas de educação básica, possibilitando sua inserção efetiva no ensino regular e disseminando conhecimentos sobre o tema nos sistemas educacionais, nas comunidades escolares, nas famílias, em todos os Estados e no Distrito Federal. (BRASIL, 2006, p. 16)

As políticas públicas de atendimento às necessidades educativas especiais, entre elas as AH/SD, recentemente aprovaram as Diretrizes Operacionais para o Atendimento Educacional Especializado na educação básica, com vistas a dar prosseguimento a uma política que terá também a finalidade de "[...] ampliar a oferta do atendimento educacional especializado aos alunos com deficiência, transtornos globais do desenvolvimento e altas habilidades ou superdotação, matriculados na rede pública de ensino regular" (BRASIL, 2009, p. 2). 


\section{Sobre conceito, diagnóstico e ação docente}

Segundo a literatura especializada, pessoas com AH/SD têm perfis psicológicos e comportamentais consideravelmente diferentes da população em geral. Isso traz implicaçôes significativas tanto para a identificação quanto para o atendimento especializado destas, em quaisquer âmbitos de ação. A identificação se motiva pela busca do desenvolvimento das habilidades e para a seleção e promoção de experiências educacionais adequadas a cada um (PROCOPIO et al., 2010). Â primeira vista isso parece complexo, pois, tendo perfis diferenciados, torna-se difícil a identificação dessas pessoas. Entretanto, são características peculiares ao indivíduo com AH/SD que tornam possível reconhecer este sujeito social em meio aos demais.

Quanto ao conceito de AH/SD, há uma grande confusão deste com o conceito de genialidade (BRASIL, 1995), porém são conceitos distintos. Gênio é aquele que apresenta um extraordinário e ímpar desempenho em uma determinada área do conhecimento, reconhecido como de alto valor pela sociedade. Já o superdotado é a pessoa que apresenta aprendizagem acima da média, criatividade e envolvimento com o que faz (Renzunlli, 1986). Além disso, pode ser que ele nunca se destaque em uma determinada área, enquanto se destaca em outras. Segundo o modelo triádico de Renzulli (que norteia as políticas públicas nacionais para a área), a $\mathrm{AH} / \mathrm{SD}$, ao menos a intelectual, inclui três características básicas: elevada capacidade intelectual, criatividade e motivação.

A inteligência deve ser superior à média, ao menos em um desvio, para que o sujeito já possa começar a ser definido como superdotado. A criatividade se manifesta pelo processamento permanente da informação e pode adquirir uma elevada projeção social em seus resultados; expressa-se, preferencialmente, na solução original dos problemas e mais ainda em sua busca (problem finding). A motivação indica uma disposição ativa para a conclusão de um trabalho, mas também significa se sentir agradavelmente atraído pela tarefa (componente emocional), estabelecer metas e planos (componente cognitivo) e aceitar a insegurança e o risco inerente a essa tarefa (perspectiva de futuro). (IZQUIERDO, 2007, p. 387)

Ainda segundo Renzulli (1986), tanto a criatividade quanto a motivação dependem da criação de situaçôes adequadas e do estímulo, e é nessa perspectiva que autores como Mönks et al. (1986) introduzem elementos 
como a escola, a família e os colegas como partes fundamentais dessa interatividade.

A identificação do aluno com AH/SD envolve testes psicométricos; levantamento de características; questionários para o aluno, professor e responsáveis; observação do comportamento da criança ou do adolescente; entrevistas com todos os envolvidos no processo de ensino. Todavia, dois tipos de erro (tipo I e tipo II) podem ser cometidos na identificação dos superdotados: o tipo I - caracterizado por identificar uma criança como superdotada, quando, na verdade, não é; o tipo II - caracterizado por deixar de diagnosticar alguém como superdotado, quando, na verdade, é.

Para se reduzirem os erros, segundo Izquierdo (2007), devem ser levados em conta certos fatores:

1.Não devemos esquecer que a definição da superdotação nunca é absoluta, mas relativa; 2 . A superdotação não é uma característica unívoca, como a altura corporal, por exemplo; 3 . As características individuais em uma área específica - matemática, por exemplo - não são idênticas ao rendimento extraordinário em outro âmbito - por exemplo, música; 4. A exatidão na identificação sempre depende da idade. Em uma criança sempre faltará a estabilidade e consistência da conduta de um adulto como indicadores da identificação. (IZQUIERDO, 2007, p. 389)

A partir daí, outros aspectos devem ser considerados no planejamento do diagnóstico do superdotado:

a) definição clara das áreas nas quais se deseja identificar a superdotação;

b. escolha dos indicadores de uma superdotaçáo potencial; c. estabelecimento das fontes de informação para cada um dos indicadores; $d$. seleçâo dos instrumentos específicos para medir os indicadores, de acordo com as diferentes fontes de informação; e). determinação dos critérios para equilibrar as diferentes informaçôes adquiridas e poder combiná-las entre si. (ROEDELL; JACKSON; ROBINSON, 1989, p. 49)

$\mathrm{O}$ trabalho com a AH/SD precisa envolver dinâmicas e metodologias que levem o aluno ao enriquecimento curricular, isto é, que façam com que ele aprofunde seus conhecimentos, principalmente nas áreas em que tiver maior afinidade. Os programas e práticas voltados para esse aluno servem para dar um atendimento especializado em consonância com suas habilidades e potencialidades, movimento esse que deve acontecer no contraturno ou no mesmo turno da escola frequentada (BRASIL, 2009). 
Entretanto, as instituiçóes de ensino ainda não estão preparadas para isso, pois grande parte dos professores e gestores escolares se encontra em processo inicial de capacitação nesta área, sem contar que muitos outros profissionais não se interessam por acharem que o aluno com $\mathrm{AH} / \mathrm{SD}$ náo tem necessidade de um atendimento específico. Dessa forma, as escolas se encontram fomentando o estabelecimento de uma prática de atendimento a esse aluno e, neste cerne, se concebem investimentos como o Atendimento Educacional Especializado (AEE).

Com a proposta do $\mathrm{AEE}$, as triagens menos complexas poderão ser feitas nas próprias escolas, e os centros, tais como o Núcleo de Atividades de Altas Habilidades/Superdotação (NAAH/S), terão um papel de polos orientadores e não mais de atendimento.

Cabe explicitar que o NAAH/S, apesar de existir na maioria das capitais brasileiras, ainda não está acessível a todas as escolas. Atualmente, o NAAH/S faz o reconhecimento dos alunos superdotados e talentosos nas escolas regulares, atuando como espaço de possível enriquecimento e aprofundamento curricular para estes alunos que fazem parte de comunidades excluídas do sistema educacional, pois precisam de motivações específicas (PROCOPIO et al., 2010). Nesse espaço, os alunos têm a possibilidade de conhecer um pouco mais sobre as áreas de seu interesse, podendo realizar atividades orientadas nessas áreas.

\section{Política pública educacional nacional e processo de escolarizaçáo}

De acordo com as Diretrizes Curriculares Nacionais, a Inclusão Escolar necessita de que as instituiçôes de ensino apresentem uma nova postura (BENITE et al., 2009). Para que isso ocorra, essas instituiçôes devem modificar sua prática em todos os sentidos, ou seja, propor mudanças no seu projeto pedagógico, no currículo escolar, na metodologia de ensino, na avaliação, nas atitudes dos educandos e educadores.

A organização escolar e os serviços de apoio dizem respeito às adaptaçóes em nível do projeto pedagógico, pois buscam o oferecimento de condiçóes estruturais tanto para a sala de aula quanto para o indivíduo. Tais adaptaçôes são pequenas modificaçóes que o professor pode fazer em relação aos métodos e aos conteúdos, podendo compreender desde a reorganização do projeto político-pedagógico da escola até a do sistema escolar como um todo, considerando as adaptaçóes necessárias à inclusão e à participação 
efetiva dos alunos com necessidades educativas especiais nas atividades escolares.

Para que haja resultado na inclusão de alunos, tanto com AH/SD como os demais alunos com necessidades educativas especiais, é necessário que não só o professor ou aluno façam mudanças em seu cotidiano, é preciso bem mais que isso. A escola deve mudar seus paradigmas e estar aberta para as necessárias mudanças em seu projeto pedagógico. Para os alunos com AH/SD são indicadas mudanças pedagógicas que ofereçam programas de enriquecimento escolar de aprofundamento de estudos, cuja finalidade é de ajustar o ensino ao nível do desenvolvimento real dos alunos.

Se os alunos com AH/SD tiverem oportunidades de enriquecer e/ ou aprofundar conteúdos curriculares e o seu nível de desempenho escolar ficar muito distanciado do nível dos companheiros de turma, surge a possibilidade da aceleração de estudos como alternativa administrativa, que envolve práticas pedagógicas para a busca da adequação social e escolar do aluno. A aceleração de estudos é um tipo de programa de atendimento educacional especializado que pode ser utilizado quando a avaliação da aprendizagem realizada na escola evidencia que o aluno demonstra competências, habilidades e conhecimentos em níveis de desenvolvimento efetivo para além dos evidenciados por seus pares em nível escolar.

Entre os objetivos da aceleração de estudos, segundo Delou (apud FLEITH, 2007), encontram-se:

- ajustar o ritmo de ensino às potencialidades dos estudantes, a fim de se desenvolver um trabalho ético racional;

- fornecer um nível apropriado de desafio escolar a fim de evitar o tédio oriundo da repetição das aprendizagens;

- reduzir o período de tempo necessário para o estudante completar a escolarizaçáo tradicional, incluindo-se a entrada precoce na escola ou na universidade.

É fato que a possibilidade de aceleração de estudos fez surgir a necessidade de uma terminalidade escolar fora dos padróes estabelecidos para a maioria dos alunos, ou seja, "terminalidade específica para aqueles que náo puderem atingir o nível exigido para a conclusão do ensino fundamental, em virtude de suas deficiências, e aceleração para concluir em menor tempo o programa escolar para os superdotados" (BRASIL, 1996). 
São necessárias, então, adaptaçóes metodológicas e didáticas, que dizem respeito a agrupamentos de alunos, métodos, técnicas e estratégias de ensino-aprendizagem, avaliação e atividades programadas. Pode ser a adoçáo de métodos e técnicas de ensino-aprendizagem específicos para cada aluno; a utilização de procedimentos e instrumentos diversos de avaliaçáo da classe; o apoio físico, visual, verbal e gestual ao aluno, a fim de propiciar a realização das atividades escolares e do processo avaliativo. $\mathrm{O}$ apoio pode ser oferecido pelo professor regente, da sala de recursos, itinerante, ou pelos próprios colegas (BRASIL, 2009; VILELA-RIBEIRO e BENITE, 2010).

Além disso, atividades individuais complementares podem ser realizadas na própria sala de aula, nas salas de recursos ou por meio do atendimento itinerante. Sobre o atendimento itinerante cabe considerar que é uma modalidade de atendimento de educação prevista em lei (BRASIL, 1996): prevê serviços de apoio especializado na escola regular para atender às particularidades da clientela de educação especial, currículos adaptados e flexibilizados, métodos, técnicas e recursos educacionais específicos. $\mathrm{O}$ atendimento itinerante atua como um elemento facilitador da inclusão (PELOSI, 2000).

Outro ponto é a introdução de atividades complementares específicas para o aluno, individualmente ou em grupo, que possam ser realizadas nas salas de recursos ou por meio do atendimento itinerante. E, ainda, a necessidade de eliminar atividades que náo beneficiem o aluno ou restrinjam sua participação ativa e real, ou eliminar as que ele esteja impossibilitado de executar. É preciso ofertar um ensino que faça sentido na vida do aluno, para que ele possa se envolver com aquilo que está sendo feito em sala de aula.

Dessa forma, aos gestores cabe a implementação desse processo, possibilitando a execução de açóes que facilitarão a inclusão escolar (IE), pois

[...] os gestores da Educação têm papel de primordial importância, já que é a eles que compete a decisão política de construir um sistema educacional que seja respeitoso e responsivo às necessidades educativas especiais dos alunos com altas habilidades/superdotação. É aos gestores, também, que compete elaborar o planejamento estratégico que lhes permitirá implementar, no ritmo e na intensidade possíveis, o preparo dos professores e dos demais profissionais da Educaçáo, bem como as adaptaçôes curriculares que se mostrarem necessárias. (BRASIL, 2002, p. 27) 
O trabalho do professor na área das altas habilidades/superdotação se traduz em desafios e requer uma postura de mediador do processo de aprendizagem, principalmente porque as características apresentadas geralmentesuperam as expectativas previstas. Esse profissional deve ter flexibilidade na conduta pedagógica e nas relaçóes entre seus alunos, possibilitandolhes o desenvolvimento de talentos e habilidades, oportunizando desafios e contextos interessantes que motivem a aprendizagem. Enfim, de acordo com Virgolim (2007), esse professor deveria encorajar a produtividade criativa e intensificar as experiências em relação a "todos os estudantes e não só aos que se destacam por suas capacidades intelectuais superiores” (p. 17).

As especificidades intrínsecas às necessidades educativas especiais precisam ser contempladas na formação inicial e continuada dos professores. Estes, na formação dos alunos, como os que se encontram em situação de $\mathrm{AH} / \mathrm{SD}$, devem explorar a criatividade, já que "ela permeia as mais distintas atividades humanas, expressando-se nas mais diferentes esferas, níveis e contextos" (ALENCAR, 2007, p. 156). Ou seja, "deve-se privilegiar a pluralidade do processo e isto se faz sob a ótica da heterogeneidade dos sujeitos para a qual ela é desenvolvida" (PROCOPIO et al., 2010, p. 4).

Importa esclarecer que o termo "aluno em situação de AH/SD" tem o mesmo sentido de "aluno em situação de deficiência", que na atualidade é proposto por vários autores (BENITE et al., 2009) e difere de "portadores de necessidades especiais". Este último também apresenta uma perspectiva institucionalizada em relação àqueles que se enquadram nesta referência, isto é, portar algo e não ser alguém, como o segundo, que se reporta à situação da pessoa (QUADROS, 2003).

A formação voltada para o âmbito da Inclusão Escolar (IE), num sentido específico das $\mathrm{AH} / \mathrm{SD}$, não deve se limitar apenas à realizaçấo de atividades concretas que abordem a criatividade, ou seja, não focar somente aspectos objetivos, mas contemplar também os subjetivos inerentes à criatividade destes alunos, tais como liderança, psicomotricidade e artes (ALENCAR, 2007).

Cabe esclarecer que concordamos com Gonzalez-Rey, ao apresentar a subjetividade como um

[...] sistema complexo produzido de forma simultânea no nível social e individual, [...] não associada somente às experiências atuais de um sujeito ou instância social, mas à forma em que uma experiência atual adquire sentido e significação dentro da constituição subjetiva da história 
do agente de significação, que pode ser tanto social quanto individual. (REY, 2003, p. 202)

Deste modo, defendemos que pensar a ação docente a partir da subjetividade dos alunos com $\mathrm{AH} / \mathrm{SD}$ nos leva à elaboração de atividades que possibilitem o desenvolvimento de suas habilidades (PROCOPIO et al., 2010).

A formação dos professores repercute tanto no desenvolvimento dos alunos com $\mathrm{AH} / \mathrm{SD}$ quanto no dos alunos do ensino regular. Por essa razão se faz mister que esse profissional frequentemente reflita sobre suas açóes pedagógicas e que estas promovam "a capacidade criativa de seus alunos, incorporando aquelas práticas que considere mais apropriadas para facilitar a aprendizagem e o desenvolvimento integral do aluno" (ALENCAR, 2007, p. 157). Nesse sentido, a formação deve ocorrer sob uma perspectiva que contemple parcerias colaborativas, pelo fato de que

nesta estrutura todos os atores colaboram através do uso coletivo de dados ou ideias, de correspondências ou discussóes no grupo de estudo, de visitas ou da execução de um projeto e da integração posterior dos resultados e da análise. Desta forma a parceria apresenta a singularidade de atuar como estrutura emergente, ou seja, própria do sistema complexo e dinâmico não linear. (BENITE et al., 2008, p. 22)

Além disso, um professor que tenha como costume refletir sobre suas açóes deve fazê-lo respeitando o dinamismo da escola (levando-se em consideração todo o ambiente escolar e não somente a sala de aula, pelo fato de o aluno com $\mathrm{AH} / \mathrm{SD}$ não apresentar habilidades apenas acadêmicas, mas também produtivo-criativas) e da sala de aula, pois é nesse ambiente heterogêneo que se encontra a diversidade contemplada pela IE . Assim, tornam-se notórias as limitaçóes intrínsecas deste movimento de ensino e aprendizagem que pode interromper o desenvolvimento dos alunos, independentemente de sua excepcionalidade, estando estes em classes regulares ou não.

Em sua formação, esse profissional deve ser preparado para proporcionar "um atendimento educacional especial para que as habilidades desse grupo $[\mathrm{AH} / \mathrm{SD}]$ possam se desenvolver ou estas permanecerão inertes" (PROCOPIO et al., 2010, p. 4).

Em outras palavras, a formação dos professores para a inclusão deve:

a) admitir as "diferenças individuais, claramente manifestadas em 
sala de aula" (METTRAU e REIS, 2007, p. 495), lugar ativo e específico dos processos de auto-organização e do desenvolvimento das inter-relaçóes;

b) reconhecer o outro em processos de interação social constituídos na dialogicidade, que não elimina as diferenças, mas as respeira e as acolhe formando o todo da educação.

Especificamente, como nenhum professor nasce predestinado a ser educador de superdotados, é conveniente que ele passe por uma preparação que acreditamos dever englobar os seguintes elementos: domínio dos contéudos, desenvolvimento de competências educacionais, desenvolvimento de atitudes positivas para com a criança superdotada. Ora, mas isso não é necessário no trabalho do educador com todos os alunos de uma sala de aula?

\section{Referências}

ALENCAR, E. M. L. S. O papel da escola na estimulação do talento criativo. In: FLEITH, D. S.; ALENCAR, E. M. L. S. (Org.). Desenvolvimento de talentos e altas habilidades: orientação a pais e professores. Porto Alegre: Artmed, 2007.

BENITE, A. M. C.; NAVES, A. T.; PEREIRA, L. L. S.; PROCOPIO, M. V. R.; FRIEDRICH, M. Formação de Professores de Ciências em Educação Especial num Ambiente de Rede de Colaboração. In: III Congresso Brasileiro de Educação Especial e IV Encontro da Associação Brasileira de Pesquisadores em Educação Especial. São Carlos. Livro de Programas e Resumos, 2008.

BENITE, A. M. C.; PEREIRA, L. L. S.; BENITE, C. R. M.; PROCOPIO, M. V. R.; FRIEDRICH, M. Formação de Professores de Ciências em Rede Social: uma Perspectiva Dialógica na Educação Inclusiva. Revista Brasileira de Pesquisa em Educação em Ciências, v. 9, n. 3, p. 1-21, 2009.

BRASIL. Ministério da Educação. Lei de Diretrizes e Bases da Educação Nacional. LDB n. 5.692, de 11 de agosto de 1971.

BRASIL. Ministério da Educação. Diretrizes gerais para o atendimento educacional aos alunos portadores de altas habilidades/superdotação e talentos. Brasília, 1995. 
BRASIL. Ministério da Educação. Diretrizes operacionais para o atendimento educacional especializado na educação básica, modalidade educação especial. Conselho Nacional de Educação, Parecer CNE/CEB n. 13/2009. Brasília, 2009.

BRASIL. Ministério da Educação. Documento orientador: execução da ação. Brasília, 2006.

BRASIL. Ministério da Educação. Garantindo o acesso e permanência de todos os alunos na escola: alunos com necessidades educacionais especiais. $\mathrm{v}$. 1. Brasília, 2002.

DELOU, C. M. C. Educaçáo do aluno com altas habilidades/superdotação: legislação e políticas educacionais para a inclusão. In: FLEITH, D. S. (Org.). A construção de práticas educacionais para alunos com altas habilidades/ superdotação: orientação a professores. Brasília: Ministério da Educação, Secretaria de Educação Especial, v. 1, 2007. p. 25-39.

GAMA, M. C. S. S. Educação de superdotados: teoria e prática. São Paulo: EPU, 2006.

GONZÁLEZ REY, F. Sujeto y subjetividad: una aproximación históricocultural. Madrid, ES: Ediciones Paraninfo, 2003.

IZQUIERDO, A. A criança superdotada: conceito, diagnóstico e educação. In: GONZÁLEZ, E. (Coord.). Necessidades educacionais especificas. Porto Alegre: Artmed, 2007.

METTRAU, M. B.; REIS, H. M. M. S. Políticas públicas: altas habilidades/ superdotação e a literatura especializada no contexto da educação especial/ inclusiva. Ensaio: avaliação e políticas públicas da educação, v. 15, n. 57, p. 489-510, 2007.

MÖNKS, F. J.; VAN BOXTEL, H. W.; ROELOFS, J. J.; SANDERS, M. P. M. The Identification of gifted children in secondary education and a description of their situation in Holland. In: SÉLLER, K. A. y FELDHUSEN, J. F. (Eds.). Identifyind and Nurturing the Gifted. An International Perspective. Toronto: Hans Huber, 1986. p. 39-66.

PEREZ, S. G. P. B. Mitos e crenças sobre as pessoas com altas habilidades: alguns aspectos que dificultam o seu atendimento. Cadernos de Educação Especial, v. 2, n. 22, p. 45-59, 2003. 
PROCOPIO, M. V. R.; BENITE, C. R. M.; CAIXETA, R. F.; BENITE, A. M. C. Formação de professores em Ciências: um diálogo acerca das altas habilidades e superdotação em rede colaborativa. Revista Eletrónica de Enzeñanza de las Ciencias, v. 9, n. 2, p. 435-456, 2010.

RAFANTE, H. C.; LOPES, R. E. Educação e psicologia: as pesquisas de Helena Antipoff e o ensino primário em Belo Horizonte na década de 1930. In: VI Congresso Luso-Brasileiro de História da Educação: Percursos e Desafios da Pesquisa e do Ensino de História da Educação. UberlândiaMG: Anais, p. 1-14, 2006.

RENZULLI J. S. The three-ring conception of giftedness. A developmental model for creative productivity. In: STERNBERG, R. J.; DAVIDSON, J. E. (Eds.). Conception of figtedness. Cambridge: Cambridge University Press, 1986.

RENZULLI J. S. What makes giftedness? Reexamining a definition. Phi Delta Kappan, v. 60, n. 3, p. 180-184, 1978.

ROEDELL, W. C.; JACKSON, N. E.; ROBINSON, H. B. Gifted young children. New York: Teachers College Press, 1989.

VILELA-RIBEIRO E. B.; BENITE, A. M. C. A educação inclusiva na percepção de professores de Química. Ciência e Educação (Unesp - impresso), v. 16, p. 341-350, 2010.

VIRGOLIM, A. M. R. Altas habilidades/superdotaçâo: encorajando potenciais. Brasília: Ministério da Educação, Secretaria de Educação Especial, 2007.

Recebido em: 10 abr. 2012

Aceito em: 15 maio 2012 